\title{
Globalisation influence on higher education in Kazakhstan and Russia (on the example of Engineering University)
}

\author{
A. Sarsenbayeva ${ }^{1, *}$ and $I$. Makarikhina ${ }^{2}$ \\ ${ }^{1}$ KAZGUU School of Liberal Arts, M. Narikbayev KAZGUU University, Nur-Sultan, 010000, \\ Kazakhstan \\ ${ }^{2}$ Novosibirsk State University of Architecture and Civil Engineering (Sibstrin), Novosibirsk, 630099, \\ Russia
}

\begin{abstract}
Globalisation is a controversial issue in education in terms of its positive or negative impact. The given article presents the review of the existing literature with regard to the benefits that globalization brought to Kazakhstani and Russian higher education and some concerns arose. The authors of the article analyze such educational phenomena pluses as university autonomy, academic mobility, university rankings and English language proliferation. Substantial modernization of higher education content in accordance with the requirements of society and the state to the specialists' education level, including foreign languages is necessary in the conditions of the economic, socio-political and social relations transformation. The revision of traditional paradigm in the general system of higher education is due to the objective need of society for an individual, aware and practically realizing his vocation and purpose in various types and international practice arising. Regarding the concerns that accompany the process of globalisation of higher education in Kazakhstan and Russia, the article considers and refutes the issues that come from the popularity of English language, the probability of colonization of Kazakhstani culture and brain drain.
\end{abstract}

\section{Introduction}

Globalisation is an absolutely complex and versatile process which has many definitions depending on the field of consideration. P. W. Jones defines globalisation as "the organization and integration of economic activity at levels which transcend national borders and jurisdictions" [1]. This process implies the access to global market of world states and their integration into the world economics. The fast spread of this phenomenon is caused with the emergence of new means of information communication andtransportation, and technological breakthroughs. Globalization is an ambivalent phenomenon which has own proponents and supporters. The main argument of those who are against this process is that globalization threats the national development, usually, of developing and underdeveloped countries and they see that as a new form of colonisation [2]. However, there are those who

\footnotetext{
* Corresponding author: michmacha@mail.ru
} 
entirely support the phenomenon due to its multiple benefits. One of the benefits is that globalization promotes multi-cultural cooperation at all levels. Another benefit is that globalization fosters the fast sharing of knowledge and skills by that contributing to the knowledge mobility [2], which is a multi-dimensional and interactive knowledge exchange that can have different ways. The mobilization of knowledge can happen through the dissemination of knowledge by means of research publications and conferences, academic mobility and education [3].

Globalization has influenced many fields of society ranging from politics to economics, and education is not the exception. Globalization of education is characterized with the desire to achieve "excellence, quality and accountability in education" [4]. Lifelong learning, knowledge economy and education for all have become the priorities as they help to achieve the main goal of contemporary education which is the training of a global citizen who must have enough knowledge and skills to compete at the global labor market and integrate into global community [2]. That is why, such ambition puts the stress on the quality of education for whose measurement different indicators were created by OECD, UNESCO and other international organizations.

The desire to train competitive human capital and produce knowledge made most of the world countries to reform their educational systems and fit them into the international standards. The reformation of education systems is not completely beneficial process because for some countries the transition is quite painful. The developed countries started to invest more financial resources into their education which increased the "innovations and productivity", whereas developing and underdeveloped countries do not succeed because of the insufficient literacy of human resources and shortage of funds [5].

Having received independence, in 1991, Kazakhstan set the ambitious goal to become the top 30 developed countries in the world by 2050 and education is supposed to lift the country into this level. The achievement of the goal seemed to be impossible without the changes in the education system, where the higher education had to undergo significant reformation. Today, Kazakhstan higher education system does not resemble the system that existed more than 20 years ago. The government abolished part-time postgraduate and 5years undergraduate education, partially decentralized the governance of higher educational institutions, built international relationships with many top-notch university, established the first autonomous university with leading faculty staff who translate their knowledge and experience around the country and the list of changes is quite long. All these changes occurred for successful integration into the global education area and providing the sustainable development. However, as in many other countries the globalisation of education in Kazakhstan is not welcomed by all citizens as there are some questions that should be raised. Therefore, the given paper will analyze such key issues of globalization as the Bologna Process, university rankings and English language proliferation which positively influence the education in Kazakhstan being the cause of multiple reforms. On the other hand, the essay demonstrates some sceptic concerns that exist in the society and cause their distrust in the existing reforms or policies.

\section{The global Bologna process}

Globalization of education means that the education systems of the countries are standardized "under one roof" [6]. The same can be said about the Bologna process. It is considered that globalization process accelerated the migration of labor forces and such phenomenon requires the recognition of qualifications of specialists who gain their education in different countries [7]. Such facilitation of employability is one of the goals of the Bologna process, i.e. the European Higher Education Area (EHEA), and reasons for its creation. 
Kazakhstan pursuing the goal of successful integration into the global economy signed the Bologna Declaration in 2010 which caused great reforms in the higher education. The Bologna process implies such main development directions as university autonomy, students and staff mobility, system of credits, three cycle system and quality assurance.

The development of university autonomy is highly necessary as it favorably influences the education performance of the institutions by means of realization of the organizational autonomy, staff autonomy, financial autonomy and academic autonomy. Up to day, according to the law passed in 2018, the universities in Kazakhstan have received the status of public universities, semi-public universities and private universities [8].

Academic autonomy gives the universities the right to design their own academic programs in terms of the language of instruction and content. However, the state still defines the $30 \%$ of the programs content [8]. The opportunity to develop owns academic programs are beneficial because they are designed in accordance with the employers' needs, and also requirements of quality assurance agencies. Moreover, it raises the competitive environment among the universities to make them more attractive and strivingfor-quality in order to recruit more students. What is more, academic autonomy allows the universities to create double diploma programs with European universities which also enhance the quality of education the students get [9]. Staff autonomy permits the universities to hire those specialists who have a lot of not only theoretical but practical experience in the target field. Such specialists know the labour market and the skills which are necessary for future specialists and, consequently, may train students according to contemporary requirements. However, the staff autonomy is highly criticized in Kazakhstan as the Ministry of Education still imposes the universities to have $50 \%$ of staff with degrees. According to Gadzhiev, the dean of IT faculty at Kazakh- British Technical University, such rules are not reasonable as for some departments it is not obligatory to hire specialists with degrees [10].

Another advantage of the Bologna process is that claiming the internationally recognized specialists from the member countries, the organization makes it obligatory to pass institutional accreditations which confirm the quality of the provided academic programs and institution as a whole. The accreditation is a highly significant process “... for regulating trans-border education and global trade of educational services" [11]. Furthermore, it is also beneficial for universities as they become more accountable for their services and students who gain the opportunity to apply for work and enroll in master or $\mathrm{PhD}$ programs in international universities as their diploma will be recognized [9]. In Kazakhstan, universities may choose the quality assurance agencies themselves among the international and national organizations. At the moment, there are 10 quality assurance organizations in Kazakhstan that can have the right to work in Kazakhstan and 6 of them are from Kazakhstan, whereas 3 are from Germany and 1 is from Belgium [12]. The dominance of Kazakhstani accreditation organizations casts a doubt on the transparency of the process as there was a negative experience of corruption connected with accreditation and attestation in the past [13].

Along with facilitation of employability, the second main goal of the Bologna process is students' and faculty mobility. This goal is prioritized not only by EHEA but also Kazakhstan as it aims to "improve the quality of higher education, increase the research effectiveness, establish internal and external relationships and use world educational resources" [14]. Academic mobility in Kazakhstan is implemented via programs that students take in European universities, Erasmus + program, Bolashaq, DAAD and other international exchange programs. It should be noted that the programs that allow students to study abroad are scholarships allocated by either the host countries or funded by Kazakhstani government. 
The Bologna process brought not only the autonomy, mobility and recognition of qualifications but also the orientation to lifelong learning. According to OECD, lifelong learning is currently an integral part of higher education policy in many countries which is responsible for increasing their competitiveness in a knowledge-driven global economy [15]. In Kazakhstan, the significance of lifelong learning for the state development is fixed in the State Program of Education Development in the Republic of Kazakhstan for 20112020 which says that all conditions will be created for its realization. Lifelong learning in Kazakhstan is characterized with formal learning as three-cycled education "undergraduate - graduate - PhD” programs and distance education, non-formal learning as continuous professional development programs and online-courses, and informal learning as online courses [16]. Higher educational institutions are seen as the main organizers and supporters of the reform which are also in charge of preparing students for lifelong learning [15].

University rankings. The key issue of globalized education is the university rankings that exist across the globe. University ranking is the important indicator of how well the university performs in comparison with other universities. These rankings provide the transparency of the university activities and they are one of the main factors that influence the choice of both students who choose the most suitable place to study and institutions who are looking for the partners. The rankings build the league table of the universities that indicate which of them produce quality knowledge and contributes to knowledge society [17]. V. Brilller and Sh. Iskakova argue for the favorable use of rankings in Kazakhstan due to the transparent picture they provide [13]. They continue claiming that the university assessment and accreditation systems that were controlled by the government were not effective due to their formality and, what is more, they generated more corruption [13].

At the moment, there are two Kazakhstani universities that are present in Times Higher Education World University Rankings and 10 in QS World University ranking[18]. The presence of these university in the list of the most prestigious universities create the competition inside the country between the universities in race for applicants. As $A$. Saginatyeva and K. Kurakbayev consider, "Kazakhstan's first experience inglobal rankings has had a positive influence on the institutional behavior of the academic institutions. In general, rankings have reinforced institutional motivation to enhance quality and to achieve a better ranking position and by so doing to claim their international presence globally"[19]. They go on arguing that university rankings system positively influenced the research output [19]. It is connected with the fact that research performance is an indicator in university assessment. Moreover, realizing the significance of rankings which bring international recognition, the government on behalf of the Ministry of Education and Science encourages the universities to participate in the ranking process.

English language proliferation. The spread of English language is another positive indicator of the impact of globalization on the education in Kazakhstan. Today, English language is considered to be the world lingua franca and has the status of global language. In Kazakhstan, the language has also achieved the special status which is prescribed at the state level. The significance of English language is reflected in such state documents as State Program of Language Development and Functioning in the Republic of Kazakhstan for 2011 - 2019, Plan of the Nation - 100 concrete steps to implement the five institutional reforms of the Head of the State, Kazakhstan 2050 etc.

The proliferation of English language in Kazakhstan is caused by economic goals. According to N. Nazarbayev, the knowledge of English language will help "to successfully get integrated into the global economy", therefore, Kazakhstani people should speak in this language along with the Kazakh and Russian languages. So, it is expected that $27 \%$ of Kazakhstani population will speak English in 2019and this figure is going to rise year by year [20]. English language is taught at all levels of education starting from kindergartens and schools. Moreover, it has become the medium of instruction in such schools as 
Nazarbayev Intellectual School and Kazakh Turkish High Schools and, what is more, STEM subjects are planned to be taught in English in most of mainstream schools.

The importance of English language in higher education is also very high. To begin, English language has become the medium of instruction in many Kazakhstani and Russian universities. Such universities as Nazarbayev University, KIMEP, Kazakh British Technical University, M. Narikbayev KAZGUU University, Suleyman Demirel University, NSUACE (Sibstrin), Novosibirsk and others are offering their academic programs in English language. It is explained with the fact that the purpose of the country is to train competitive specialists and "increase the export potential of educational sector of the country" [21]. The second benefit of English language proliferation is internationalization which is a key goal for many universities and here English language serves as a tool to create English speaking environment in the universities. It brings such benefits as foreign students and faculty recruitment, mobility of students and academic staff, joint research and academic programs, and international accreditation [21]. Internationalization as whole brings the international experience to Kazakhstan and exert a favorable influence on the quality of education [22]. Another important benefit of English language spread in higher education is that the knowledge of language allows Kazakhstani and Russian researchers to publish their works in recognized journals with high impact factors, participate in international conferences and by that contribute to knowledge mobility. Moreover, according to the ex-vice-minister of education in Kazakhstan, Aslanbek Amrin, there will be a phased transition to English language for applied sciences which means that all research and expertise in these fields will be conducted only in English [23]. Such approach gives the opportunities to Kazakhstani scientists participate in the process of knowledge sharing and get international recognition.

Flexible approach to learning a foreign language and professional translation skills is introduced to optimize the process in Russian and Kazakhstani universities [9]. Nowadays a number of e-learning courses in English on the preparation of engineering and environmental specialties, scientific and technical literature translators are being prepared for publication.

\section{Results}

Talking about the contemporary positive aspects of Kazakhstani and Russian higher education caused by the process of globalisation, some concerns should be still mentioned. First of all, there is a sense to wonder who gains and who loses from the popularization of English language? Phillipson thinks that contemporary spread of English language in the status of global language serves the transnational corporations whose possible aim is to produce the consumers but not critical people [24]. Michaud \& Colpitts continue arguing that today the education systems of such Asian countries as South Korea and Japan are oriented at taking standardized tests like TOEFL, which turns English into the commodity [24]. The same might be applied for the situation in Kazakhstan and in Russia. The first actors who financially benefit from the spread of the language are the organizations that are in charge of such standardized tests as IELTS and TOEFL, for instance British Council. These exams are obligatory for application to foreign universities and such universities in Kazakhstan as Nazarbayev University and KIMEP, NSUACE (Sibstrin) in Russia. Moreover, according to the legislation, students with the IELTS certificates are free from English language entry exams for master programmes and the same is being made for the UNT (United National Testing) [25]. Such requirements create the demands for these exams among Kazakhstani population and the number of those who take the exams is growing, which consequently increase the investments into the economics of the UK, the USA and Australia. 
To continue, in Kazakhstan society there is a share of skepticism related to the globalisation as it is seen as the tool to colonize the country by the developed ones, namely Western countries. According to L. Tikley, education plays a vital role in spreading Western cultural values which, consequently, reshape the cultural identities of citizens and create 'new ethnicities' [26]. Moreover, it ensures the transfer of knowledge of Western countries to developing and underdeveloped states creating the global Western society. Such allegations seem to be unreasonable because, first of all, the same process occurs in the whole world; secondly, there are traces of not only western culture but Turkish culture too which is disseminated by Kazakh-Turkish lyceums, Suleiman Demerel University and close relationships with Turkey; thirdly, there are strong relationships with other post-soviet countries which currently have a strong influence on each other.

Another issue which threats Kazakhstan's sustainable development is the brain drain. English language proliferation and standardization of qualification frameworks make it easier for students and young specialists to immigrate to European and other countries where population is aging. Students who have just graduated from university may seek to apply for master or PhD programmes in developed countries. These countries offer the gifted students many bonuses which can be full scholarships, free accommodation and other incentives[27].

Finally, despite the excitement about access to world scientific community, there is a concern behind such publications. M. Curry and T. Lillis call English language "the global language of scholarly publishing" [28]. They argue that most of highly ranked journals accept only articles written in English and those journals that publish the articles in other languages "are excluded from prestigious journal indexes" [28]. Such tendency is alarming as local audience do not get access to these publications unless they know English and dual publication in the local languages are not allowed by the policy of the journals. Such situation implies that only those who speak English may benefit from this knowledge sharing which is quite unfair as in that case science does not meet local people's needs.

\section{Conclusion}

In 1991, when the USSR dissolved and Kazakhstan received independence, it opened its borders and got exposed to the global community at the same time. Being rich in natural resources and having an advantageous geographical position, the government understood that the country had good potential to make the transition from the developing countries to the developed ones. It could be done by adopting the market economy principles and integrating into the world community.

The development of no nation is possible without the development of the education which must be the key priority of the societal prosperity. Therefore, seeing the problems of existing education system and its inability to meet the global requirements, the state set the direction to borrow the best practices and reshape the system so that it could satisfy the modern societal needs and country's strategic goals. After at least a 30 years' period, Kazakhstan higher education system has made a huge progress towards its goal. The state has signed the Bologna Declaration and entered the European Higher Education Area. Such step allowed the universities to introduce the double-diploma programmes, develop own academic programs that meet the labour market needs, organize students' and staff mobility etc. Today, all Kazakhstani universities are accredited by either national or international bodies which aim to confirm that the academic programs of the institutions and institutions themselves assure the quality and meet international standards. In pursuit of recruiting more both local and international students, the universities participate in world rankings, such as QS, THE, Shanghai and others, in order to be more recognized at the international level. All these reforms were established with the view to provide quality education. It is no 
surprising to note that the lack of quality is the plague of education systems in post-soviet countries due to the corruption, Soviet legacy and state control that did not let the universities advance. Such disadvantageous reputation is difficult to improve, but the state has succeeded and the fact that Kazakhstani universities can be found in the world ranking lists serve the vivid example of that. Another instance of the positive influence of globalisation is opportunity to take part in the knowledge mobility at the global level by means of presenting the results of the research at conferences, publishing in international journal and students' and faculty mobility.

Talking about the concerns, it should be said that although publications in international journals are criticized in terms of their usefulness to the local population because they are available only in English, Kazakhstani citizens are improving their English language competence as they understand that it is the global language and it opens many doors for them. In addition, such issue as brain drain about which Kazakhstan society is anxious has a positive side. Due to the globalisation every brain drain can automatically turn into the brain gain as it promotes the circulation of experiences, skills and knowledge exchange. Last but not least, fears of being colonized by developed countries due to globalisation might not be justified as global education prepares 'global citizens' with the set of skills and knowledge making them competitive at the global market and helping contribute to the global communities [29].

To sum up, globalisation has mostly positive impact on the development of Kazakhstani education as it triggered the reforms that promote the quality education and help Kazakhstan to achieve economic prosperity. However, the work that has been done is just the beginning and there is a lot to do. Kazakhstan has ambitious goals to compete equally with the developed countries and best practices brought to education system should assist the achievement of the goal.

\section{References}

1. P. Jones, Globalisation and internationalism. Democratic prospects for world education edsM Crossley, P Broadfoot and M Schweisfurth Changing Educational Contexts, Issues and Identities (Education Heritage)1st Edition. (Routledge) 239-299 (2011)

2. S. Bakhtiari, Globalization and education: Challenges and opportunities (2011) https://www.researchgate.net/publication/242621870_Globalization_And_Education Challenges And Opportunitiesp. 96

3. I. Silova, R. Read, K. Mundy, The mobilization of knowledge.Six decades of the comparative and international education society (Dordrecht: Springer) 155-165 (2016)

4. J. Zajda, International handbook on globalisation, education and policy research global pedagogies and policies. (Dordrecht: Springer) (2005)

5. F. Stewart, Globalisation and education, International Journal of Educational Development $16 \quad$ (4)

https://www.sciencedirect.com/science/article/pii/S073805939787232X

6. S. Misra, Implications of globalization on education (2012) https://www.researchgate.net/publication/269699451_Implications_of_Globalization_o n_Education

7. T. Baigabatov, T. Bondartsova, Higher education in Kazakhstan in the light of the Bologna process (2013) http://mysl.kazgazeta.kz/?p=847

8. European University Association, Transition to university autonomy in Kazakhstan (2018) 
9. What does international accreditation give to higher educational institutions (2016) (The Tengrinews) https://tengrinews.kz/kazakhstan_news/chto-daet-mejdunarodnayaakkreditatsiya-kazahstanskim-vuzam-301035/

10. Zh. Khabdulkhabar, Higher education in Kazakhstan. What will academic freedom give students? (2019) https://informburo.kz/stati/vysshee-obrazovanie-v-kazahstanechto-dast-studentam-akademicheskaya-svoboda.html

11. ECA Accreditation in the European higher education area (2004) http://ecahe.eu/w/images/9/91/Eca-position-paper-bergen-2005.pdf

12. ENIC-Kazakhstan nd Register of recognized accreditation bodies Retrieved from https://enic-kazakhstan.kz/en/accreditation/accredited_organizations

13. V. Briller, Sh. Iskakova, University ranking in Central Asia The experience of Kazakhstan eds SP Heyneman and AJ DeYoung The Challenges of Education in Central Asia (Greenwich: Information age publishing) 257-273 (2004)

14. G. Kemelova, Academic mobility and quality of education (2012) https://kaznmu.kz/press/2012/09/19

15. I.M. Makarikhina, Improving the Didactic Competence of Teachers in The Process of Advanced Training (for example, the subject of English): author. dis. ... to-that ped. science. (M Makarikhina. - Barnaul, 2013)

16. Jr.F. Ganotice, H. Tang, G. Tsui, J.Villarosa, S.Yeung, Globalization of world university rankings and its impact on asian universities 329-344 (2016) https://doi.org/10.4018/978-1-5225-0819-9.ch017

17. Study in Kazakhstannd https://www.timeshighereducation.com/student/where-tostudy/study-in-kazakhstan

18. A. Saginatyeva, K.Kurakbayev, The Impact of global university rankings on higher education management and policy in Kazakhstan, Evaluation in Higher Education 6, 2, $47-57$ (2012)

19. B. Maudarbekova, Z. Kashkinbayeva, Internationalization of higher education in Kazakhstan, Procedia - Social and Behavioral Sciences 116, 4092 - 4097 (2014)

20. Y.Yeralina, The impact of internationalization of higher education on the competitiveness of economy in the countries of Central Asia: Comparative analysis (2016) https://articlekz.com/en/article/15181

21. A.Akhmetbekov, Applied research will be conducted in English language in Kazakhstan (2017) https:/www.inform.kz/ru/prikladnye-nauchnye-issledovaniyaperevedut-na-angliyskiy-yazyk-v-kazahstane_a3076979

22. B.Colpitts, English as a lingua franca: Globalization, ownership, and the diversification of English (Kwansei Gakuin University Humanities Review 120, 125-131 (2015)

23. D.Ramazanova, UNT-2019: pupils with IELTS and TOEFL will be free from taking English language exam (The Today) (2018) http://today.kz/news/zhizn/2018-1121/772279-ent-2019-ot-sdachi-anglijskogo-yazyika-osvobodyat-uchenikov-s-ielts-itoefl/

24. L.Tikley, Globalisation and education in the postcolonial world. eds M Crossley, P Broadfoot and M Schweisfurth Changing Educational Contexts, Issues and Identities (Education Heritage)1st Edition (Routledge) 293-297 (2001)

25. A.Zhatkabayeva, J. Zhatkanbayeva, E. Zhatkanbayev, The impact of globalization on "brain drain" in developing countries, Procedia - Social and Behavioral Sciences 47, 1490 - 1494 (2012) 
26. M.Curry, T.Lillis, The dangers of English as lingua franca of journals (2018) https://www.insidehighered.com/views/2018/03/13/domination-english-languagejournal-publishing-hurting-scholarship-many-countries

27. S.Chinnammai, Effects of globalisation on education and culture (2005) https://pdfs.semanticscholar.org/d08e/7f2bd7cfec087a99eec6336096dd4c6aa1ce.pdf 